\title{
Concept of External Costs Calculation in the Ports: Environmental Impacts
}

\author{
Alen JUGOVIĆ, Merica SLIŠKOVIĆ, Luka VUKIĆ
}

\begin{abstract}
Calculation of external costs in ports is often based on the estimation of necessary input values. Such approach leads to the large differences between results of different researchers and does not show exactly the share of the individual polluter. Internalization of external costs as a tool of current European Union transport policy requires accurate data in order to realize the principle "polluter pays". Authors emphasize three main guidelines: air pollutant emission as a source of pollution, fixed number of people as an exposure to pollution and a certain way of interpretation of results. The calculation is based on values of emissions from ships rather than on values measured in air. Parameters for calculation are previously known from the ship registers, spreadsheets, and public documents, and only the fuel consumption measurement is desirable. The concept avoids the uncertainties in research as much as possible, enables identification of polluter and its share in total pollution, and could make valuation procedure more precise and fair.
\end{abstract}

Keywords: exhaust emissions; external costs; maritime transport; port-city

\section{INTRODUCTION}

The methodology of calculating external costs has always been an intriguing question. Differences in the results of calculation, which may be significant, depend on the choice of method, but also on the availability of data that is included in the calculation as well as on the estimation of relevance of available data, author's scientific attitude, and sometimes interests which author represents [1-6]. The importance of external costs in the implementation of the European Union's transport policy [7] requires the calculation of external costs as objective and realistic as possible in order to be charged fairly and proportionately by those who are responsible for them. In this paper a concept of calculation based on exclusively measurable input values that could correspond to the mentioned criteria is proposed.

\section{EXTERNAL COSTS}

External costs are defined as those costs which arise when social or economic activities of one group of persons have an impact on another group and when that impact is not fully accounted, or compensated for, by the first group [1]. In the case of transport, external costs are costs to society and without policy intervention, are not taken into account by the transport users [8]. For instance, in the case of transport, these costs comprise the costs of air and noise pollution which the individual user will not take into account in deciding how many journeys to make [2].

\subsection{External Costs in the Transport Sector}

The most important categories of external costs in ports are:

- environmental costs,

- emergencies costs (accidents),

- costs of congestion.

Environmental costs comprise air pollution costs, noise costs, costs of pollution on water and soil, climate change costs, costs of protected and urban areas, the impact of traffic capacities on environment and energy dependence costs. Air pollution cost is reflected in human health, damage to structures and materials, loss of crops and damage to forests and the impact on biodiversity and ecosystems. Noise is the next kind of cost, a product of negative effect of transportation. Its level of intensity and time of exposure can affect some degree of disturbance of the population and the physical and psychological effects on health. The costs caused by climate changes are related to additional protection of the sea due to rising sea levels (laws and conventions) and global warming. The cause of global warming is creating so-called greenhouse effect due to excessive carbon emissions. The cost of transport capacity relates to the environmental impact caused by manufacturing or construction, maintenance and disposition of transport and infrastructure capacities. Costs in urban areas are divided into effects of separation of certain types of traffic (e.g., pedestrian and motorized traffic), and the problem of the scarcity of available space and fees for insufficient space for the non-motorized area (e.g., bicycle). The costs of energy dependence are the result of unequal share of net imported energy and transportation options. In the case of accidents costs, the external part is connected with the part of costs that are not covered by risk-oriented insurance premiums, like material damages, administrative costs, medical costs, production losses and the so-called risk-value as a proxy to estimate pain, grief, and suffering in monetary values. The costs of congestion are reflected through an extension of time travel, lack of accurate assessment of traveling time, increased fuel consumption, increased emissions, increased infrastructure spending and means of transport, reducing of service levels, an increase of stress and accidents $[9,10]$.

\subsection{External Costs in Ports}

Regarding port congestion, accidents, environmental and climate changes are considered costs. Congestion costs are considered a negligible component, due to overcapacity of existing port infrastructure with respect to the current demand. Regarding accident costs, fortunately rare, they need specific considerations. Marginal noise costs in ports are assumed to be negligible because most of the activities take place outside densely populated areas. Environmental impacts regard both air and water pollution. Regarding air 
impacts, ship emissions to atmosphere comprise ozone and aerosol precursors ( $\mathrm{NO} x, \mathrm{CO}, \mathrm{VOCs}, \mathrm{SO} x$, etc.) and the emissions of greenhouse gasses $\left(\mathrm{CO}_{2}\right)$. The effects of these pollutants are well known [11]. $\mathrm{SO}_{2}$ and $\mathrm{NOx}$ can become converted into sulfate and nitrate particles. Exposure to them is associated with increased mortality and morbidity. Shipping emissions in ports contribute notably to the formation of ground-level ozone, especially in the Mediterranean region, with effects on human health and crop yields. The deposition of sulfur and nitrogen contribute to exceedances of critical loads of acidity. Nitrogen oxides lead to eutrophication, which affects biodiversity, both on land and coastal waters. Finally, emissions from ships contribute to climate change [2].

External costs in the port occur from ships, port equipment, port industry and rail and road transport. The variables that we encounter when calculating external costs are different with respect to their source. Regarding the damages coming from the port equipment as well as those relating to the port industry they are known and stable values that change only with the length of operating time. Regarding rail and road transport their contribution to the external costs is related to the time of departure and arrival and work mainly on standard vehicles with known characteristics. If we calculate their external cost, which is negligible in relation to the ships' one (we could instead imagine a train and a truck that are in operation 24 hours and calculate their external cost) then we will act according to the same principles as for the ships.

External costs coming from ships are difficult to calculate because there are multiple changeable variables due to different types of ships, engine, fuel, and sometimes unknown mechanical settings. The problem of calculating the external costs in port actually means to calculate the external costs of the ship in port.

Transportation external costs in port are estimated by two main approaches, i.e. the bottom-up and top-down, with their own advantages and weaknesses. The top-down approach is more suitable for calculating average costs, but the extraction of marginal costs is rather difficult. This approach is more representative on a general level and it provides a comparison between modes of transport. On the other hand, the cost function has to be simplified and cost allocation to specific traffic situations and the differentiation for vehicle categories is rather aggregated. When dealing with marginal cost valuation, the more suitable is a bottom-up approach. It is more accurate with potential for differentiation, but costly and difficult to aggregate to get average figures for transport clusters or national averages. In practice, a mixture of bottom-up and top-down approaches (with representative data) should be combined [2]. When speaking about the calculation of external costs of emission impacts in the ports, the greater amount of uncertainty is found. It can be confirmed by the two alternative ways for calculating impacts. The first methodology relies on the CAFE/ExternE approach, which constitutes the most comprehensive and reliable work on this matter. Exposure-response functions (FER) are applied on the observed concentration levels that are attributable to ships, multiplied per the relevant population exposed. On the other hand, the second methodology follows the line suggested by [12]. It is based on risk-response functions (RR) that measure the increase of probability of an event following a $10 \mu \mathrm{g} / \mathrm{m} 3$ increase in the 83 concentration levels above the threshold that can be considered as "normal".

The huge discrepancies in results suggest that a high level of uncertainty is present, and the estimates in these two approaches need to be considered with some caution (Tab. 1.).

Table 1 Total external cost due to impact of air pollution from ships (€/year) [2]

\begin{tabular}{|c|c|c|}
\hline & ExternE/CAFÉ & Martuzzi \\
\hline PM10 & 7.188 .210 & 2.160 .225 \\
\hline PM2.5 & 14.044 .470 & 8.403 .834 \\
\hline SOx & 1.652 .142 & \\
\hline PAH & 1.066 .575 & \\
\hline
\end{tabular}

\section{ANALYSIS OF UNCERTAINTIES}

In order to make the input values more stable for calculation of external cost in ports, the analysis should identify the uncertainties on the side of the source of pollution and on the side of the exposure to pollution as well as to the internalization procedures.

\subsection{Uncertain Sources}

Studies on environmental impacts from maritime transport activities are focused mainly on air emissions due to the lack of accurate measurement of other impacts. Air pollution is the best measurable part of environmental impacts that we can scientifically validate. But it is also marked with uncertainties (wind direction and speed, air temperature and pressure, etc.) which have an effect on air pollution levels. So, it is hard to determine the amount and the source of pollution, whether its origin is inside or outside of the port, what are the real values of the pollutant that make damage and external costs and who is responsible for them. It is recognized that ozone is the main pollutant having effects on agriculture and horticulture sectors [13]. As for health impacts, this method is valid for all activities entailing air pollution, not only maritime transport. The other environmental impacts like noise, water pollution, waste, erosion, loss of biodiversity, etc. participate with a lower percent of the total external costs in the ports than air pollution [2]. Noise damage is hard to measure [14] and it is negligible compared to the total damage. In general, there is no detailed information on emissions in water. Contrary to the air emissions, it is difficult to calculate emission factors in water as well as its source. Even more difficult is to estimate the generation of waste from the ships in ports, erosion and loss of biodiversity. The damage is based on assumption that the values are not representative and objective, due to the inability of accurate measuring.

The concept of the approach is based on the values of emissions from the ship rather than the values measured in the air. With this methodology, results would be more reliable, the emission of harmful gas determined for each ship so, a percentage of the total damages relating to one particular ship can be provided. There is the intention of less estimation and more measurement in the calculation of external costs. 


\subsection{Uncertain Exposure}

Emission of the toxic air pollutants threatens people, nature and other resources essential to maintaining normal activities and life. Urban and industrial pieces of city centers have grown around the ports. As the values of pollutants are quite indefinite and depend on various influences on their sources so the degree of exposure is also changeable and unsure. The degree of exposure varies considerably with respect to land transport and depends on ports distance from city center [2].

In this concept, due to their constant migration (students, tourists, etc.), fixed number of the exposed population (e.g. according to the last census) has been taken for stable calculation of the total external costs. It is essential to measure the whole population because determining the exact number of people who are exposed to the emission from sources that interest us is not accurate, relevant and scientifically valuable. The lifestyle, type of work, apartment location, previous diseases and finally the impact of weather forced us to consider that only the total population corroborates the scientific approach to solving this problem. The results are reliable, representative and, although not quite accurate, they are comparable to the other ports and regions.

\subsection{Weaknesses of Internalization Procedures}

It is naive to assume that there is a single policy capable of fixing internalization of external costs since the complexity of the real world cannot be captured fully by elementary economic theory [15]. The projects like ExternE, performs a valuable function in showing concretely what is meant by external cost, and the importance of internalizing such costs in the pricing system [16], or like the Clean Air for Europe (CAFÉ) program [17], which is the most up-to-date and comprehensive study of health impacts. Regarding the monetization of the effects of air pollution on crop yields, a damage cost approach is chosen. Once the effects of ozone on these are isolated, one can consider the value of the lost produce to infer the economic damages entailed by pollution [2]. Except the size of the damage we cannot determine who is responsible for the damage and who will pay the cost. This is the consequence of calculation with variables mixed from different sources. By their very nature, however, the estimates will always include degrees of uncertainty, and this will be a barrier to their use. The ExternE project has performed a valuable function in showing concretely what is meant by external cost, and the importance of internalizing such costs in the pricing system. In addition, its technical nature (and, thus, the difficulties of understanding the information) and disagreements associated with methodological issues will continue to limit the ExternE's use [16]. Citing the papers by [4] and [5] Fouquet and the authors comment: What is the external cost? Is it 29 Euros per ton, as ExternE estimates? \$2/ton, the lower of the range in figure 1.2, or $\$ 75 /$ ton, or $\$ 220 /$ ton? We still do not know [6].

The concept accepts existing methods for valuing the damages in internalization procedure because better methods do not exist. However, there is an intention to influence the input values to become as more scientific as they can. This is the reason why input values should be cleaned by the exclusion of all uncertainties.

\subsection{Input Values Quality}

Existing concepts of external cost calculation of their environmental impacts are mainly based on measuring real values of different pollutants in order to estimate the real cost of damage. Enormous complexity and variety of internalization measures currently in place make it impossible to give a detailed account of each and every one of them [18]. There is a real need for internalization of external costs and there are efforts to calculate them exactly and fair. In these efforts, the calculation is made with uncertain, variable and unsafe input values suggesting an unscientific approach. This uncertainty does not take place only in attempts to the valuation of natural damages, as we could expect, despite the development of more and more sensitive methods for it (ExternE/CAFÉ, Martuzzi) [2]. They are also in the scientific values measured by instruments as always when we calculate with many changeable variables at the same time and when they can affect each other. Some damages like erosion, loss of biodiversity and climate changes need a long time to become visible and there is not a unique instrument to measure them. Such input values are unstable and they are not suitable for the scientific approach. The results are not comparable among different investigations even in the same case, consequently neither outside of it.

There is a question what we can do to resolve the problem or how to convert unstable input values into stable? We try to calculate the real cost of damage. Do we get it after internalization procedure? It is much better to talk about the estimated costs. It means that we do not manipulate with the real costs at all, but we try to get closer to them as much as possible. If we temporarily give up the existing internalization procedure of external costs, let's assume we do not need to know the "real" cost of damage, which would not be exactly known even with the standard procedure as already mentioned. We can manipulate only with the measurable input values that come from a unique source, that affect the unique target and that it can present high percent of total damages, enough to be reliable indicators. We calculate only measured damage, not real damage. Such values are stable and more reliable and suitable for monetization procedure. The final results are probably lower than they really are but if necessary, they can be increased by the appropriate percentage, the part which is not represented by chosen indicator. Although the results after internalization procedures are not real in their absolute numbers the shares or the percentages of every impact are real, reliable and preserved. Regardless of it, the results of every further such investigation show the direction if the damage is higher or lower as well as the level of successfulness after taken actions.

\section{ELABORATION OF THE CONCEPT}

The concept presumes the intervention on three points: air pollutant emission as a source, fixed number of exposed people as an exposure and a certain way of presentation and interpretation of results. 


\subsection{Air Pollutant Emission versus Air Pollution}

Air pollution participates with the highest percentage of external costs of transport. Author [18] found its participation of $48.1 \%(782 / 1625$ mil€) as the highest among environmental impacts in Europe, but if climate change is excluded (the impact is global, the damage does not attack only one country, it is our common cost, it is much more variable) then air pollution participated with $70.5 \%$ (782/1109 mil€). Author [19] noted the damage of $69.8 \%$ of air pollution in ports in the EU (39830 mil€) and $70.5 \%$ in the world (183721 mil€) including costs of climate damage. It is also the damage which is easy measured unlike the measurement of water and soil pollution $(0.22-0.25 \%$ of share), erosion, loss of biodiversity and climate (20-30\% of share). Noise has an impact on residential property values [20] and on the quality of life, but generally, the damage has a local character and it participates with a low percent of the total damage. It seems that air pollution is the best scientific indicator of all environmental impacts in the ports. The sources of air pollution in the ports are different. They come from ships, port services, port industry and rail and road traffic. When we measure the pollutants in the air we do not know how many pollutants come from each particular source in ports and how many belong to the basal levels coming from traffic and industry outside the port. Uncertainties about impact estimates (and consequently about external cost valuation) derive from uncertainties related to the slope of the "dose-response" function and the contribution to ambient concentration of a given pollutant emission. So, we want to calculate only air pollution coming from the port to estimate the damage and the external cost. But it cannot be calculated measuring the levels of pollutants in the air. It could be made by measuring air pollutant emission from every pollutant source in the port. That procedure would be expensive and actually unnecessary knowing that the pollution always comes from the combustion of mineral fuel [2].

\subsubsection{Type of Fuel Oil} 2.

The most important types of fuel oil are shown in Tab.

Table 2 Fuel classification [21]

\begin{tabular}{|c|c|}
\hline Code & Name \\
\hline BFO & Bunker fuel oil \\
\hline MDO & Marine diesel oil \\
\hline MGO & Marine gas oil \\
\hline GF & Gasoline fuel \\
\hline
\end{tabular}

If we know the type of oil, we also know the amounts of pollutants that are released by combustion per unit of the fuel in the control area [22]. There are some useful formulas for it as well as the spread sheets with necessary data.

$\mathrm{SO}_{2}$ emission is proportional to the fuel oil consumption and the content of sulfur in the oil by the following theoretical fuel specific emission rate equation:

$\mathrm{SO}_{2}$ emission $=21 \times S$, in $\mathrm{kg} \mathrm{SO} \mathrm{S}_{2}$ per ton of fuel oil where $S$ is the percentage mass sulfur content in the fuel [23].

The emission of $\mathrm{CO}_{2}$ is proportional to the fuel oil consumption by the following fuel specific emission rates shown in Tab. 3. [24].

Table 3 Specific emission rates of $\mathrm{CO}_{2}$ depending on the type of fuel [24]

\begin{tabular}{|l|l|}
\hline \multicolumn{1}{|c|}{ Fuel } & \multicolumn{1}{c|}{$\mathrm{CO}_{2}$ rate } \\
\hline Heavy Fuel Oil (HFO) & $3.114 \mathrm{t}$ per $\mathrm{t}$ oil \\
Light Fuel Oil (LFO) & $3.151 \mathrm{t}$ per $\mathrm{t}$ oil \\
Diesel Oil/Gas Oil (DO/GO) & $3.206 \mathrm{t}$ per $\mathrm{t}$ oil \\
Liquefied Natural Gas (LNG) & $2.750 \mathrm{t} / \mathrm{t}$ gas \\
Liquefied Petroleum Gas (LPG) & $3.000 \mathrm{t} / \mathrm{t}$ Propane, $3.003 \mathrm{t} / \mathrm{t}$ Butane \\
LNG/DO: & $2.78 \mathrm{t} / \mathrm{t}$ fuel \\
\hline
\end{tabular}

Particulate emission mostly depends on sulfur content [23] and it is calculated by the formula defining particulate emission factor $(P E F)$ in $\mathrm{g} / \mathrm{kWh}$ :

$P E F=0.26 \times 0.081 \times S+0.103 \times S^{2}$,

where $S$ is the sulfur content in \%.

The fuel specific NOx emission rate for diesel engines depends on different factors of which one is the engine type. Another factor is the fuel type, as example shift from oil to gas. Slow speed engines have generally higher NOx emissions compared with medium speed engines [25].

\subsubsection{Fuel consumption}

The fuel consumption is the second value, which is necessary for calculation. Generally, information about the type and power of the main and auxiliary engine in ships and other equipment in port is available. The oil consumption corresponds to fuels with the specified calorific value of $42.7 \mathrm{MJ} / \mathrm{kg}$ corresponding to marine diesel oil or gas oil (MDO and MGO). It also depends on the type of engine (Tab. 4.).

Table 4 Diesel or gas oil consumption depending on the type of engine [26]

\begin{tabular}{|c|c|}
\hline Type of engine & Diesel or gas oil consumption \\
\hline Slow speed engines & $155-175 \mathrm{~g} / \mathrm{kWh}$ \\
Medium speed engines & $175-200 \mathrm{~g} / \mathrm{kWh}$ \\
High speed engines & $195-225 \mathrm{~g} / \mathrm{kWh}$ \\
Gas turbines & $240-300 \mathrm{~g} / \mathrm{kWh}$ \\
\hline
\end{tabular}

If heavy fuel oil (HFO) with a calorific value of 40.5 $\mathrm{MJ} / \mathrm{kg}$ is used, the values are $5.7 \%$ higher (42.7/40.5). For a de-rated engine, they are approximately $4 \%$ lower [28].

If there is a need for more independent selection data, the specific oil consumption ( $S F O C$ ) is used as the selection criteria. The value of $S F O C$ for the new data could be calculated in most cases.

$S F O C=\frac{A E_{x} \text { fuelatberth } \mathrm{kg}}{A E_{x} \text { poweratberth } \mathrm{kW}}$.

To verify the value of the $S F O C$ only the data from the first auxiliary engine $(A E)$ was considered. All values between 0.15 and $0.45 \mathrm{~kg} / \mathrm{kWh}$ were thought to be within an acceptable range [26]. The pollutant emission correlates with the type of engine and type of oil producing certain values of each pollutant factor as it is shown in Tab. 5 . 
Table 5 Default basic emission factors ( $\mathrm{kg} / \mathrm{t}$ of fuel) for using in the simplified methodology [21]

\begin{tabular}{|l|c|c|c|c|c|c|}
\hline \multicolumn{1}{|c}{ Engine types } & $\mathrm{NO} x$ & $\mathrm{CO}$ & $\mathrm{CO}_{2}$ & VOC & PM & SO $x$ \\
\hline $\begin{array}{l}\text { Steam turbines - } \\
\text { BFO engines }\end{array}$ & 6.98 & 0.431 & 3200 & 0.085 & 2.50 & 60 \\
\hline $\begin{array}{l}\text { Steam turbines - } \\
\text { MDO engines }\end{array}$ & 6.25 & 0.6 & 3200 & 0.5 & 2.08 & 20 \\
\hline $\begin{array}{l}\text { High speed diesel } \\
\text { engines - BFO }\end{array}$ & 70 & 9 & 3200 & 3 & 1.5 & 60 \\
\hline $\begin{array}{l}\text { Medium speed } \\
\text { diesel engines - } \\
\text { BFO }\end{array}$ & 57 & 7.4 & 3200 & 2.4 & 1.2 & 60 \\
\hline $\begin{array}{l}\text { Slow speed diesel } \\
\text { engines - BFO }\end{array}$ & 87 & 7.4 & 3200 & 2.4 & 1.2 & 60 \\
\hline $\begin{array}{l}\text { High speed diesel } \\
\text { engines - MDO }\end{array}$ & 70 & 9 & 3200 & 3 & 1.5 & 20 \\
\hline $\begin{array}{l}\text { Medium speed } \\
\text { diesel engines - } \\
\text { MDO }\end{array}$ & 57 & 7.4 & 3200 & 2.4 & 1.2 & 20 \\
\hline $\begin{array}{l}\text { Slow speed diesel } \\
\text { engines - MDO }\end{array}$ & 87 & 7.4 & 3200 & 2.4 & 1.2 & 20 \\
\hline Gas turbines & 16 & 0.5 & 3200 & 0.2 & 1.1 & 20 \\
\hline
\end{tabular}

There are known data about engine fuel consumption per $\mathrm{kWh}$ as well as about the amount of pollutants released per ton for certain type of fuel [2]. The emission factors for auxiliary engines during transit, maneuvering and hoteling depending on the type of fuel used are shown in Tab. 6 . [27].

Table 6 Auxiliary Engine Emission Factors ( $\mathrm{g} / \mathrm{kWh}$ ) [27]

\begin{tabular}{|l|c|c|c|c|c|c|c|}
\hline \multicolumn{1}{|c|}{ Fuel } & $\mathrm{CH}_{4}$ & $\mathrm{CO}$ & $\mathrm{CO}_{2}$ & $\mathrm{NO}_{x}$ & $\mathrm{PM}_{10}$ & $\mathrm{PM}_{2,5}$ & $\mathrm{SO}_{x}$ \\
\hline $\begin{array}{l}\text { Marine Distillate } \\
(0,1 \% \text { S })\end{array}$ & 0.09 & 1.10 & 690 & 13.9 & 0.25 & 0.35 & 0.40 \\
\hline $\begin{array}{l}\text { Marine Distillate } \\
(0,5 \% \text { S })\end{array}$ & 0.09 & 1.10 & 690 & 13.9 & 0.38 & 0.35 & 2.10 \\
\hline Heavy Fuel Oil & 0.09 & 1.10 & 722 & 14.7 & 1.50 & 1.46 & 11.10 \\
\hline
\end{tabular}

The whole fuel consumption in the port per unit time is the best value for calculation. Daily or monthly fuel consumption of port services and industry are also known, but the same information for ships, trucks and trains is not always available. Total fuel consumption at berth should be measured on arrival and departure.

\subsubsection{Concept of the Calculation}

Depending on the type of collected data, we probably need the third value, the uptime of the engine. The uptime of ship's auxiliary engine is the time while in port.

Finally, we take into account the values of air pollutant emission in the port as a result of whole fuel consumption, assuming that the whole amounts of pollutant really make damages and there are not losses or dilutions. Although not quite accurate, the input values are scientifically determined. They are stable, verifiable, reproducible and without uncertainty.

We have now the formula for the amount of air pollutant emission in the port (APE in $\mathrm{kg})$ :

$A P E=t F C \times b E F$,

where $t F C$ reflects the total fuel consumption while in port (ton) and $b E F$ reflects basic emission factor $(\mathrm{kg} / \mathrm{t})$ from Tab. 5.

We have also several auxiliary formulas when we do not know the fuel consumption $(F C)$ :
$A P E=P_{a x} \times E F_{a x} \times t$,

where $P_{a x}$ reflects the auxiliary engine power $(\mathrm{kW}), E F_{a x}$ reflects auxiliary engine emission factor $(\mathrm{g} / \mathrm{kWh})($ Tab. 6) and $t$ reflects uptime $(h)$ or

$t F C=P_{a x} \times S F O C \times t$,

where SFOC reflects specific fuel oil consumption $(\mathrm{kg} / \mathrm{kWh})$ or

$t F C=a F C \times t$,

where $a F C$ reflects average fuel consumption per hour for a certain engine $(\mathrm{kg} / \mathrm{h})$.

When the important facts remain unknown, when the measurement is impossible, there are also other useful tables by which the estimation can be easier. If we calculate the fuel consumption as a function of total deadweight tonnage, then it is known in the database of each vessel. The estimation of the main engine horsepower for different vessels is assumed to follow the equations based on Tab. 7. [28].

Table 7 Estimation of the main engine horsepower depending on the total dead weight tonnage (dwt) and type of vessel [28]

\begin{tabular}{|l|c|}
\hline \multicolumn{1}{|c|}{ Type of vessel } & Horsepower estimation \\
\hline container vessels & $0.80 \times \mathrm{dwt}-749.4$ \\
tankers & $0.1083 \times \mathrm{dwt}+6579$ \\
bulk carriers & $0.0985 \times \mathrm{dwt}+6726$ \\
Ro/Ro-ships & $0.288 \times \mathrm{dwt}+3046$ \\
\hline
\end{tabular}

The load factors for auxiliary engines in maneuvering and hoteling (berthing) modes are based on [29] and [30] reports and it is shown in Tab. 8.

Table 8 Load factors for auxiliary engines depending on the type of vessel

\begin{tabular}{|l|c|}
\hline \multicolumn{1}{|c|}{ Type of vessels } & Load factors \\
\hline container vessels & $18 \%$ \\
tankers & $26 \%$ \\
bulk carriers & $10 \%$ \\
Ro/Ro-ships & $26 \%$ \\
\hline
\end{tabular}

Table 9 Auxiliary to main engine power ratio

\begin{tabular}{|l|c|}
\hline \multicolumn{1}{|c|}{ Type of vessels } & Power ratio \\
\hline container vessels & 0.220 \\
tankers & 0.211 \\
bulk carriers & 0.222 \\
Ro/Ro-ships & 0.191 \\
\hline
\end{tabular}

There is also available information for the ratio by which we can estimate the power of the auxiliary engine [22] (Tab. 9).

All these data are as useful as they lead to escape from a scientific approach to uncertainty. The estimation can never replace the measurement. There is a particular danger, when existing estimation derives from the fact which has already been determined by estimation. The most important measurement which should be done is the sounding of the ship fuel tanks just after arrival and just before departure. Every effort of a certain ship to reduce emissions should be noted and calculated no matter how much it is effective. These efforts are very useful in comparative studies on external costs calculation. 


\subsubsection{Preparation of Results for Internalization Procedure}

The internalization procedure programs require input values shaped as concentrations. The concept manipulates with results as amounts. These amounts are dispersed in the surrounding region. The borders are spread horizontally to the border of the region where the exposed people who were taken into account live (f.e. borders of the town). The vertical border is determined after agreement how big tropospheric part of air affects human health. It is not important for the concept of the exact height of the column of air if it is 3,5 , or $10 \mathrm{~km}$ above the earth until we do not calculate with absolute values in the internalization procedure. It is important that it is always the same to enable us to compare the results. Now, we have all parameters needed to calculate the volume of polluted air and the concentrations of pollutants in that air from their known quantities already. If we want to calculate with absolute values and real costs then we can use sophisticated MM5/SMOKE/CMAQ programs with their advantages and disadvantages [31, 32]

\subsection{All People versus Exposed People}

The environment exposed to the influence of pollutants and the damages, which should be valued and transformed into the monetary form, are also full of uncertainties which need to be cleaned up in another approach. There is the same principle as it has been described for input values: we need a unique target, easily measurable, unchangeable and representative. Among many targets, the number of exposed people is the best. The port is often situated in the center of town, which grows around it. Regardless of different risks for people in a town with regard to where, when, how much and who is exposed to the pollutants we should count that all of them are exposed, all of them are affected equally, by the same dose of pollutants and during the same time. We are aware of the deviations of such results, but the calculation with more variables, especially in the field of environmental destruction and climate changes brings much more uncertainty so, the comparable concept seems more useful. The data are used from the last census. It is not performed frequently (maybe every ten years) so there are enough opportunities to get comparable papers. The damages in the industry and nature are excluded because the measurement is difficult, indirect and unsure.

\subsection{Presentation and Interpretation of Results}

The comparability of results is the most important contribution of the concept. Although it does not manipulate with absolute values, after the procedure performed to reduce emissions, it can show the direction if the pollution is higher or lower in comparative studies. It can also compare external costs between two or more ports after same or different such procedures bringing valuable experience. To make the results comparable the external cost should be always presented per unit as it is presented in Table 10. It should also calculate the external cost per inhabitant.

The last column shows that total external cost is four times higher than the port revenue. It shows how far we are from the sustainability and how much work there is in the future. Presenting the results in such format, we enable easy comparison with the results of any next investigation and determine the real direction of sustainable development.

Table 10 Port eco-efficiency performance [33]

\begin{tabular}{|c|c|c|c|c|c|}
\hline \multicolumn{2}{|c|}{} & \multicolumn{3}{|c|}{ ECO-EFFCIENCY PERFORMANCE } \\
\hline $\begin{array}{c}\text { Exhaust } \\
\text { emissions }\end{array}$ & $\begin{array}{c}\text { External } \\
\text { external }(€)\end{array}$ & $\begin{array}{c}\text { ext per } \\
\text { cost } \\
\text { tons of } \\
\text { cargo } \\
(€ / 1,000 \\
\text { tons })\end{array}$ & $\begin{array}{c}\text { Emission } \\
\text { external } \\
\text { cost per } \\
\text { TEU } \\
(€ / 1,000) \\
\text { TEU) }\end{array}$ & $\begin{array}{c}\text { Emission } \\
\text { external } \\
\text { cost per } \\
\text { ship call } \\
(€ / \text { call })\end{array}$ & $\begin{array}{c}\text { Emission } \\
\text { external } \\
\text { cost per } \\
\text { port } \\
\text { revenue } \\
€ / \text { million } \\
\text { Euros })\end{array}$ \\
\hline $\mathrm{NO} x$ & $47,744,771$ & 2,149 & 36,812 & 5,231 & 964,875 \\
\hline $\mathrm{SO} x$ & $62,661,360$ & 2,820 & 48,313 & 6,865 & $1,266,324$ \\
\hline $\mathrm{VOC}$ & 146,191 & 7 & 113 & 16 & 2,954 \\
\hline $\mathrm{PM}{ }_{2,5}$ & $70,378,105$ & 3.167 & 54,263 & 7,710 & $1,422,272$ \\
\hline $\mathrm{CO}$ & 1,846 & 0,08 & 1,42 & 0,2 & 37 \\
\hline $\mathrm{CO}_{2} \mathrm{High}$ & $31,500,803$ & 1,418 & 24,288 & 3,451 & 636,600 \\
\hline Total & $212,433,076$ & 9,560 & 163,791 & 23,273 & $4,293,063$ \\
\hline
\end{tabular}

According to the concept mentioned above the results have relative significance and do not present the real damage. Consequently, when valuated, they do not show the real external costs. The input values of ship emissions are oversized as they are toxic in their full amount. The number of exposed people is also oversized as they are all affected. So, the absolute value of air pollution damage is presented as a higher percentage of total damage than it really exists, but some other damage has been excluded at the same time. However, the results are representative knowing that air pollution, among other environmental impacts, participates with around $50 \%$ of the total damage. The water, soil and noise pollution, erosion and loss of biodiversity participate all together with less than $10 \%$ and measurement of them is difficult and based on estimation [18]. The rest belongs to climate changes, which are the most difficult to estimate and have a global character so, the damage is not located in the local area, and cannot be charged only by the local port. Under these circumstances, the importance of results is greater. The damage on agricultural products and forests is not calculated (and it is much more difficult) and neither are the impacts of accidents and congestion (that are negligible in ports) but the damage on people is oversized. The emissions from industry and rail and road traffic should be added under the same principle. So, the results of air pollution damage would have to be inside their average percentages. Even if not, there is a guiding principle that the fair payment of external costs is based on measurable impacts of damage and the ship air pollutant emissions in the ports are the best measures for it.

\section{CONCLUSIONS}

There are several approaches for calculation of external costs in the ports. They are too much based on estimation at both ends of calculation and are hardly comparable. Their input values are the real values, but they cannot be exactly divided among their sources.

Using the values of emissions from the ships instead the values measured in the air, the input values in external cost internalization procedure would be more scientific. It 
enables simple calculation of the part how much certain ship call contributes to total external costs in the port.

Using the fixed number of exposed people and fixed borders of affected area, and presenting the results per unit they become comparable with the results of the next or any other investigation. The success of any action taken in order to reduce external costs in this way can be objectively assessed regardless of local conditions and specifics.

This approach allows insight into how many of external costs belong to each source of pollution and so the principle that the damage is paid by the one who did it can be applied.

The parameters for calculation are previously known from the ship's registration data as well as from the tables with calculated data on emissions dependent on the fuel oil and engine types. The uptime is available at port authority and the fuel consumption measure is desirable.

The concept does not calculate with absolute values, it counts only the participation of impacts as well as the up and down movement of the costs in comparative studies. It is the consequence of strictly scientific approach and avoidance of uncertainties as much as possible. The valuation procedure with such prepared input values would be more useful and fair.

\section{REFERENCES}

[1] EC. (2005). ExternE Externalities of Energy - Methodology 2005 Update. Bickel, P.; Friedrich, R. (eds.) DirectorateGeneral for Research Sustainable Energy Systems. EUR 21951, Office for Official Publications of the European Communities, Luxembourg.

[2] Miola, A., Paccagnan, V., Mannino, I., Massarutto, A., Perujo, A., \& Turvani, M. (2009). External costs of Transportation, Case study: maritime transport. European Commission Joint Research Centre, Institute for Environment and Sustainability, European Communities, Office for Official Publications of the European Communities, Luxembourg.

[3] Martuzzi, M., Mitis, F., Iavarone, I., \& Serinelli, M. (2006). Health Impact of PM10 and Ozone in 13 Italian Cities. http://www.euro.who.int/document/e88700.pdf (4.10.2016)

[4] Tol, R. S. J. (1999). The Marginal Costs of Greenhouse Gas Emissions. The Energy Journal, 20(1), 61-81. https://doi.org/10.5547/ISSN0195-6574-EJ-Vol20-No1-4

[5] Papathanasiou, D. \& Anderson, D. (2000). Uncertainties in responding to climate change: on the economic value of technology policies for reducing costs and creating options. Imperial College Centre for Energy Policy and Technology. http://www.iccept.ic.ac.uk (14.10.2016)

[6] Fouquet, R., Slade, R., Karakoussis, V., Gross, R., Bauen, A., \& Anderson, D. (2001). External costs and environmental policy in the United Kingdom and the European Union. Centre for Energy Policy and Technology, Imperial College, London.

[7] EC, White Paper. (2011). Roadmap to a Single European Transport Area - Towards a competitive and resource efficient transport system, COM (2011) 144 final, Brussels, Belgium

[8] Maibach, M., Schreyer, C., Sutter, D., Van Essen, H. P., Boon, B. H., Smokers, R.., Schroten, A., Doll, C., Pawlowska, B., \& Bak, M. (2007). Handbook on estimation of external cost in the transport sector. Internalization Measures and Policies for all external Cost of Transport (IMPACT). CE Delft, The Netherlands.

[9] Jugović, A., Žanić Mikuličić, J., \& Maglić, L. (2014). Impact of external costs on the implementation of Motorways of the
Sea system. Scientific Journal of Maritime Research, 28, 1721.

[10] Matczak, M. (2009). Maritime Safety in European Concept of the Internalization of External Costs of Transport. International Journal on Marine Navigation and Safety of Sea Transportation, 3(2), 207-211.

[11] IMO. (2000). Study of Greenhouse Gas Emissions from Ships. Issue no. 2-31. http://unfccc.int/files/methods_and science/emissions_from_intl_transport/application/pdf $/$ imo ghgmain.pdf (15.10.2016)

[12] Martuzzi, M., Mitis, F., Iavarone, I., \& Serinelli, M. (2006). Health Impact of PM10 and Ozone in 13 Italian Cities. http://www.euro.who.int/document/e88700.pdf (4.10.2016)

[13] GOV UK. (2013). Department of Environment, Food and Rural Affairs. Impact pathway guidance for valuing changes in air quality. http://www.gov.uk/government/ uploads/system/uploads/attachment_data/file/197900/pb139 13-impact-pathway-guidance.pdf (23.10.2016)

[14] Quinet, E. \& Vickerman, R. W. (2004). Principles of transport economics. Edward Elgar, Cheltenham, UK.

[15] Eyre, N. (1997). External costs. What do they mean for energy policy? Energy Policy, 25(1), 85-95. https://doi.org/10.1016/S0301-4215(96)00124-3

[16] Abbes, S. (2007). Marginal social cost pricing in European seaports. European Transport / Trasporti Europei 36, 4-26.

[17] Hurley, F., Hunt, A., Cowie, H., Holland, M., Miller, B., Pye, S., \& Watkiss, P. (2005). Methodology for the Cost-Benefit Analysis for CAFE. Health Impact Assessment, Volume 2. http://ec.europa.eu/environment/archives/air/ cafe/activities/cba.htm (27.10.2016)

[18] Van Essen, N., Nelissen, D., Smit, M., Van Grinsven, A., Aarnink, S., Breemersch, T., Martino, A., Rosa, C., Parolin, R., \& Harmsen, J. (2012). An inventory of measures for internalizing external costs in transport. European Commission Directorate-General for Mobility and Transport, DM 28 - 0/110 - Archives B-1049 Brussels, Belgium, p.110.

[19] Maffii, S., Molocchi, A., \& Chiffi, C. (2007). External costs of maritme transport. A TRT study for the European Parliament (Committee for Transport and Tourism and E.P. Policy Department B, Structural and Cohesion Policies), 1113.

[20] Henttu, V., Lättilä, L., \& Hilmola, O. P. (2010). Financial and Environmental Impacts of a Dry Port to Support Two Major Finnish Sea Ports. Research Report 224, Lappeenranta University of Technology, Finland, 34-35.

[21] Trozzi, C. \& Vaccaro, R. (1998). Methodologies for estimating air pollutant emissions from ships. Techne report MEET RF98. http://www.inrets.fr/infos/cost319/ MEETdeliverable19.pdf (23.10.2016)

[22] Merk, O. (2014). Shipping Emissions in Ports. International Transport Forum, Paris, France, Discussion Paper No. 201420, OECD Publishing.

[23] Lloyd's Register. (1995). Marine Exhaust Emissions Research Program. London, UK.

[24] IMO. (2009). Interim Guidelines on the Method of Calculation of the Energy Efficiency Design Index for New Ships. MEPC 61/Circ. 681.

[25] Kristensen, H. O. (2012). Energy demand and exhaust gas emissions of marine engines. Project no. 2010-56, Work Package 2, Report no. 05, Technical university of Denmark. https://www.shipowners.dk/services/beregningsvaerktoejer/ download/Basic_Model_Linkarea_Link/164/wp-2-report-5energy-demand-and-emissions-of-marine-engines.pdf (20.10.2016)

[26] Hulskotte, J. H. J., Wester, B., \& Snijder, A. M. (2014). International survey of fuel consumption of seagoing ships at berth. Work package 5, Clean North Sea Shipping, Norway. 
[27] CARB. (2008). Emissions Estimation Methodology for Ocean-Going Vessels. California Air Resources Board, Planning and Technical Support Division, California Environmental Protection Agency, Sacramento, CA.

[28] EPA. (2000). Analysis of commercial marine vessels emissions and fuel consumption data. EPA420-R-00-002, US Environmental Protection Agency, Washington, D.C.

[29] Starcrest Consulting Group LLC. (2005). Port of Los Angeles baseline air emissions inventory - 2001. Prepared for the Port of Los Angeles. http://www.portoflosangeles.org/DOC/REPORT_Final BA EI_ExecSum.pdf (20.10.2016)

[30] Starcrest Consulting Group LLC. (2007). Puget Sound Maritime Air Emissions Inventory. Prepared for Puget Sound Maritime Air Forum. http://www.pugetsoundmaritimeairforum.org/uploads/Puget Sound_MaritimeAirEmissionsInventory.pdf (20.10.2016)

[31] Byun, D. W., Jang, M. D., Song, C. K., Kim, S., Cheng, F. Y., Perna, R., \& Kim, H. C. (2007). Operational evaluation of the Eastern Texas air quality (ETAQ) forecasting system based on MM5/SMOKE/CMAQ. In: Borrego, C., Renner, E.E. (Eds.), Air Pollution Modeling and its Application XVII, Developments in Environmental Science, vol. 6. Elsevier, Amsterdam, Oxford, UK, 253-263. https://doi.org/10.1016/S1474-8177(07)06217-1

[32] Čavrak, M. (2006). Air quality modeling and simulation at Rijeka's regional area. MSc Thesis, Faculty of Engineering, University of Rijeka, Croatia.

[33] Tichavska, M. \& Tovar, B. (2015). Environmental cost and eco-efficiency from vessel emissions in Las Palmas Port. Transportation Research Part E Logistics Transportation Review, 83, 126-140. https://doi.org/10.1016/j.tre.2015.09.002

\section{Contact information}

Alen JUGOVIĆ, PhD Associate professor

University of Rijeka,

Faculty of Maritime Studies Rijeka

Studentska 2, 51000 Rijeka, Croatia

E-mail: ajugovic@pfri.hr

Merica SLIŠKOVIĆ, PhD Associate professor

University of Split,

Faculty of Maritime Studies Split

Ruđera Boškovića 37, 21000 Split, Croatia

E-mail: merica@pfst.hr

Luka VUKIĆ, mag. ing. admin. nav.

Corresponding author

University of Split,

Faculty of Maritime Studies Split

Ruđera Boškovića 37, 21000 Split, Croatia

E-mail: Ivukic@pfst.hr 